\title{
Determination of Biogenic Amines and Vitamins in Urine Samples with HPLC
}

\author{
Irena Baranowska and Joanna Płonka \\ Department of Analytical and General Chemistry, Silesian University \\ of Technology, Gliwice, Poland
}

\begin{abstract}
An HPLC system for simultaneous separation and marking of biogenic amines and their metabolites from catecholamines group: dopamine (DA), epinephrine $(\mathrm{E})$, normetanephrine $(\mathrm{NMN})$, metanephrine $(\mathrm{MN})$, 3,4-dihydroxyphenylacetic acid (DOMA), 3-metoxy-4-hydroxyphenyl-glycol (MHPG), homovanillic acid (HVA) and indoloamines group: serotonin (5HT) and 5hydroxyindole-3-acetic acid (5HIAA), as well as water soluble vitamins B-1, B-2, B-3, B-6, B-12, and C has been developed. The RP18e column with RP18 precolumn and DAD serial connected with a fluorescence detector have been used. Gradient elution with acetate buffer $(\mathrm{pH}=4.66)$ with methanol has been applied. The developed system has been used for marking the examined compounds in urine samples.
\end{abstract}

Keywords: Biogenic amines, HPLC, Urine, Water soluble vitamins

\section{INTRODUCTION}

Biogenic amines are formed as a result of decarboxilation of base and inactive amino acids. These compounds are required for keeping cells alive and the proper cell processes running. In the human organism, biogenic amines perform the role of neurotransmitters. Because of their structure, these compounds can be divided into aliphatic amines

Correspondence: Irena Baranowska, Department of Analytical and General Chemistry, Silesian University of Technology, 7 M. Strzody Str. 44-100, Gliwice, Poland. E-mail: irena.baranowska@polsl.pl 
(mono- and polyamines), heterocyclic amines (imidazole amines, indoloamines), and catecholamines. A group of catecholamines include, among others, dopamine, epinephrine, and norepinephrine. Representative of indoloamines is serotonin. In modern medical diagnostics of several diseases, like cancer ${ }^{[1]}$ anorexia, ${ }^{[2]}$ and depression it is recommended to monitor the concentration of dopamine, epinephrine, and serotonin, as well as their metabolites in organic fluids. Water soluble vitamins $(C$, B-1, B-2, B-3, B-6, and B-12) perform a role of enzyme cofactors. Marking of vitamins in urine allows one, for example, to confirm medical diagnosis (anemia, hypervitaminosis) or provide substantial information in the treatment of nephrolithiasis ${ }^{[3]}$ or depression. Performed investigations revealed the dependence of water soluble vitamins consumption and their concentration in urine. ${ }^{[4]}$

Vitamin $\mathrm{C}$ is required for the norepinephrine and dopamine synthesis in organisms. ${ }^{[5]}$ Simultaneously this compound performs a role of psychological and conservative effects of dopamine antagonist due to increasing activity of dopamine antagonists. ${ }^{[6]}$ Vitamins from group B are responsible, among others, for proper nervous system functionality (B-1); ${ }^{[7]}$ ATP (adenosine triphosphate) in brain tissue production (B-2); ${ }^{[8]}$ serotonin synthesis (B-6); ${ }^{[9]}$ performing a role of homocysteine metabolism cofactors (B-6 and B-12); which is responsible for dopamine synthesis. ${ }^{[10]}$ Vitamins supplement to the diet can be part of the treatment process, thus the ability to monitor the concentration of both given vitamins and compounds, whose creation is dependent on vitamins is essential. Simultaneous marking of $\mathrm{B}$ and $\mathrm{C}$ vitamins next to dopamine allows one to monitor the performance of drugs in the treatment process.

Both biogenic amines and water soluble vitamins transit to body fluids like urine and blood. Analysis of these fluids provide the therapist essential information, which is necessary in many the treatment of diseases, due to the ability to determine the concentration of above mentioned compounds received as drugs or consumed with food. Results from literature review shows that there are chromatographic systems, which are able to determine biogenic amines ${ }^{[11-20]}$ and water soluble vitamins $^{[21-22]}$ in urine samples. However, no chromatographic system and urine sample preparation method, which allows one to determine simultaneously both biogenic amines and water soluble vitamins has been yet developed.

An analytical procedure for simultaneous determination of biogenic amines and water soluble vitamins has been developed. In this manuscript is described a procedure which allows one to prepare urine samples for simultaneous determination of compounds from two different groups. The developed chromatographic procedure allows one to obtain information about concentration of compounds from these two groups in one analysis. 


\section{EXPERIMENTAL}

\section{Reagents}

Standard solutions $\left(1 \mathrm{mg} \mathrm{mL}^{-1}\right)$ in $0.1 \mathrm{M} \mathrm{HCl}$ with $\mathrm{Na}_{2} \mathrm{~S}_{2} \mathrm{O}_{5}\left(5 \mathrm{~g} \mathrm{~L}^{-1}\right)$ of dopamine (DA), epinephrine (E), normetanephrine (NMN), metanephrine (MN), 3,4-dihydroxyphenylacetic acid (DOMA), 3-metoxy-4-hydroxyphenyl-glycol (MHPG), homovanillic acid (HVA), serotonin (5HT), 5-hydroxyindole-3-acetic acid (5HIAA) (Sigma-Aldrich) have been prepared. Standard solutions $\left(1 \mathrm{mg} \mathrm{mL}^{-1}\right)$ of ascorbic acid (C), thiamine (B-1), riboflavine (B-2), niacin (B-3), pyridoxine (B-6) and cyanocobalamin (B-12) (Sigma-Aldrich) in water have been prepared. Methanol and acetate buffer $(\mathrm{pH}=4.66)$ of HPLC grade used in this work for mobile phase preparation were purchased from Merck, Darmstadt, Germany.

\section{High Performance Liquid Chromatography Conditions}

HPLC analyses were performed using a Merck-Hitachi chromatograph equipped with L6200A pump and detectors: DAD L4500A and fluorescent L-7480. Chromatographic separations were carried out on a LiChroCARD Purospher column RP-18e, $125-3 \mathrm{~mm}$, particle size $5 \mu \mathrm{m}$ accompanied with LiChroCARD $4-4 \mathrm{~mm}$ precolumn packed with LiChrospher 100 RP-18, particle size $5 \mu \mathrm{m}$ (Merck, Germany) at room temperature.

Gradient elution with acetate buffer $(\mathrm{pH}=4.66)(\mathrm{A})$ and methanol (B) was applied. Gradient elution was as follows: minute $0-100 \% \mathrm{~A}$, minute $3-100 \% \mathrm{~A}$, minute $8-90 \% \mathrm{~A}$ and $10 \% \mathrm{~B}$, minute $23-65 \% \mathrm{~A}$ and $35 \%$ $\mathrm{B}$, minute $24-65 \% \mathrm{~A}$ and $35 \% \mathrm{~B}$, minute $30-100 \% \mathrm{~A}$. The flow rate before the $23^{\text {rd }}$ minute was $0.5 \mathrm{~mL} \mathrm{~min}^{-1}$, then until the $24^{\text {th }}$ minute increased to $0.8 \mathrm{~mL} \mathrm{~min}^{-1}$, and after the $24^{\text {th }}$ minute increased to $1.0 \mathrm{~mL} \mathrm{~min}^{-1}$. A similar chromatographic system was used by the authors previously for determination of levodopa and biogenic amines. ${ }^{[23]}$

Detection for biogenic amines has been performed with the use of a fluorescent detector with excitation wavelength of $\lambda_{\mathrm{EX}}=285 \mathrm{~nm}$ and emission wavelength of $\lambda_{\mathrm{EX}}=315 \mathrm{~nm}$. Detection for vitamins has been performed with the use of a DAD detector with the following wavelengths: $\lambda=240 \mathrm{~nm}$ for B- 1 and B-12 vitamins, $\lambda=254 \mathrm{~nm}$ for B-3, B-6, and $\mathrm{C}$ vitamins and $\lambda=274 \mathrm{~nm}$ for $\mathrm{B}-2$ vitamin.

\section{Calibration Curves}

Calibration curves for biogenic amines and vitamins in urine matrix have been prepared. Standard solutions with concentration of $0.06-2 \mu \mathrm{g} \mathrm{mL}$ 
for biogenic amines and 2-64 $\mu \mathrm{g} \mathrm{mL}^{-1}$ for water soluble vitamins have been prepared. The number of experimental points taken for regression was $\mathrm{n}=6$. Every analyte was injected thrice. The volume of the solution in every single injection was $20 \mu \mathrm{L}$.

\section{Urine Samples}

Urine samples were taken from healthy people treated with a multivitamin preparation, which contain among others vitamins from group B and vitamin C. Samples were taken three times per day-one hour, four hours, and eight hours after taking the multivitamin preparation. Simultaneously, urine samples were taken from people not treated with this multivitamin preparation. After collection, samples were frozen and stored in the refrigerator at a temperature of -22 Celsius degrees. Before analysis, samples were defrosted and centrifuged $(2500 \mathrm{rpm}, 10$ minutes). $\mathrm{A}_{18}$ column was used for extraction $(500 \mathrm{mg})$. Columns were conditioned with $2 \mathrm{~mL}$ of methanol and $2 \mathrm{~mL}$ of distilled water, acidified to $\mathrm{pH}=4.2$ with $0.005 \mathrm{M} \mathrm{HCl}$. Consequently, $1 \mathrm{~mL}$ of sample was introduced. After the urine sample passed through the stationary phase it was dried for 2 minutes. Then the analytes were eluted with $1 \mathrm{~mL}$ of water with $\mathrm{pH}=4.2$ and $2 \mathrm{~mL}$ of methanol. The eluent was dried to a dry residue, which had been consequently dissolved in $200 \mu \mathrm{L}$ of water acidified to $\mathrm{pH}=3.7$. The volume of the solution in every single injection was $20 \mu \mathrm{L}$. The applied SPE procedure has been mentioned in the literature ${ }^{[21]}$ before, but for determination of several vitamins (C, B-1, B-2, and B-6) only. For residual water soluble vitamins and biogenic amines, such a procedure has not been previously applied. Because of high concentration of amines from the physiological processes in urine samples, higher dilutions had to be applied to obtain the volume of $2 \mathrm{~mL}$.

\section{RESULTS AND DISCUSSION}

This developed and applied chromatographic system allows the separation and determination of nine biogenic amines and their metabolites, as well as five water soluble vitamins. Figure 1 shows the chromatogram of the vitamins standard with urine matrix contribution. Urine samples have been prepared with the use of the solid phase extraction method. A DAD detector with absorbance recording for different wavelengths has been used. Wavelengths have been assorted for each vitamin properly. 


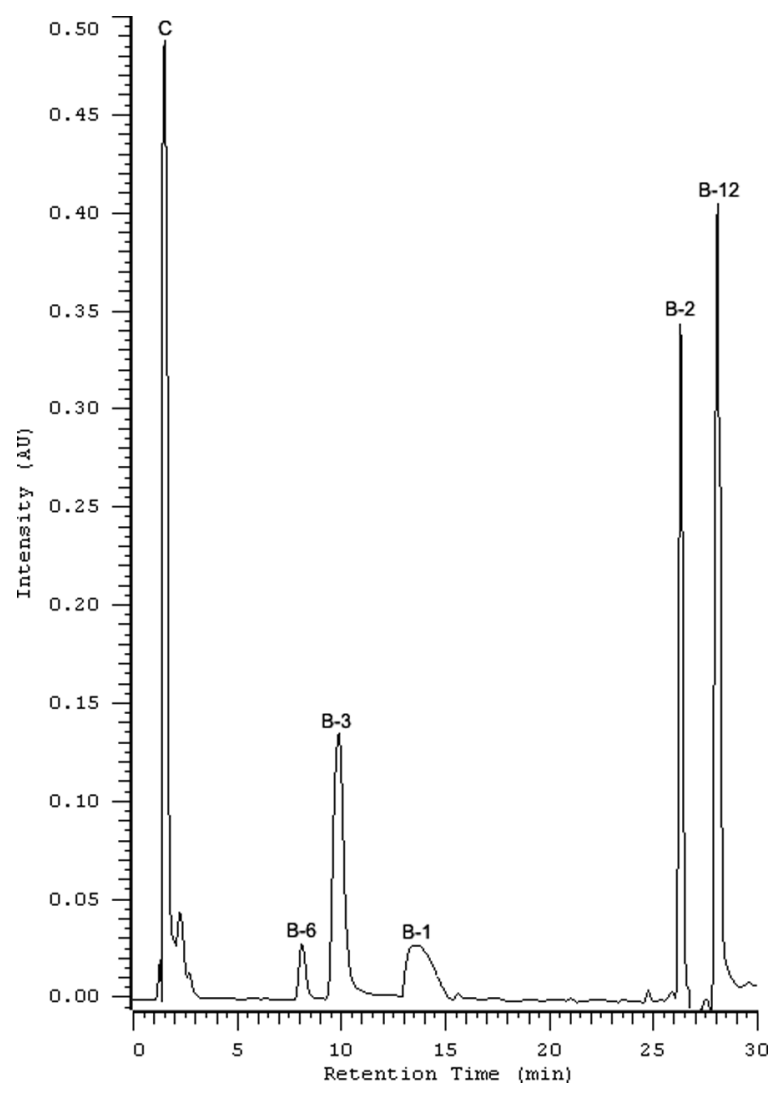

Figure 1. Chromatogram of vitamins standards.

Differences in retention times of particular analytes are considerable, which allowed one to obtain good peak separations. Simultaneously, the chromatogram recording for several different wavelengths allowed elimination of urine matrix influences.

Figure 2 shows the chromatogram of biogenic amines standards with urine matrix contribution recorded with use of a FL detector. Good separations of all amines and their metabolites have been obtained. Remaining peaks come from urine matrix, but they do not interfere with peaks of analytes.

Signal-to-noise ratio for limit of detection was 3. The LOD values range for biogenic amines was $8-10 \mathrm{ng}$ per milliliter of sample and $0.5-1 \mu \mathrm{g}$ per milliliter of sample for vitamins. Exact LOD and LOQ 


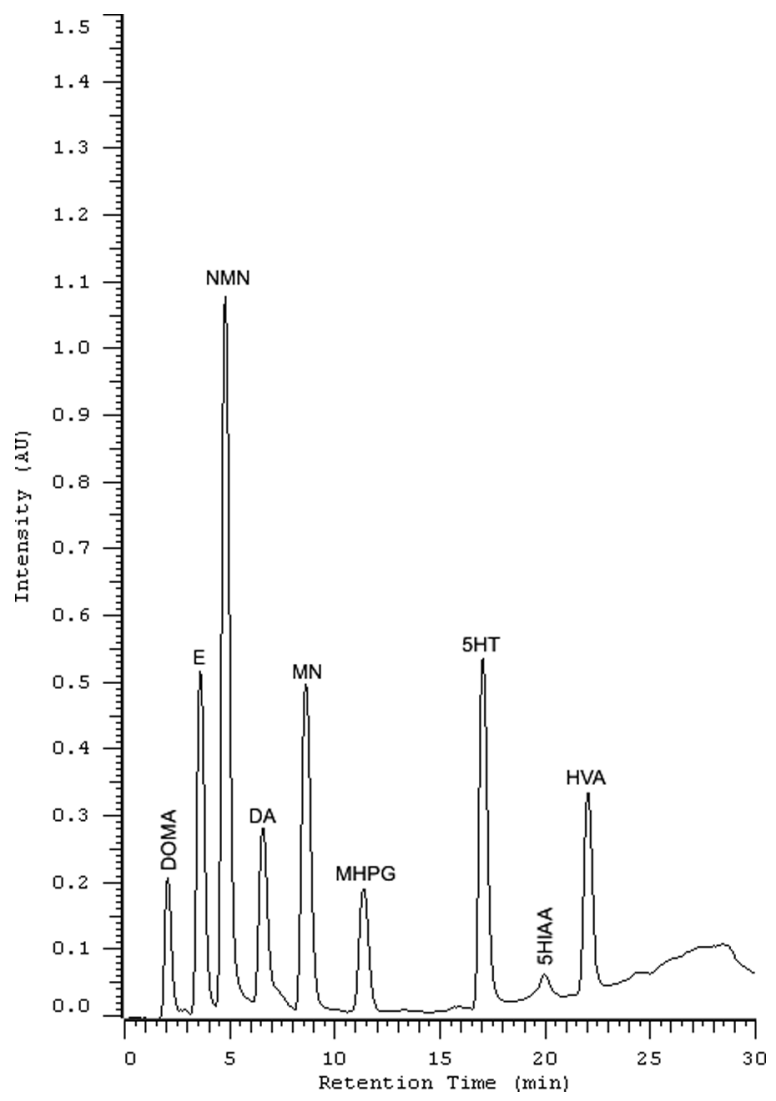

Figure 2. Chromatogram of biogenic amines standards.

values, retention times, calibration curves parameters for all analytes are presented in Table 1.

Examination of accuracy and precision of determination has been performed by adding a solution of water soluble vitamins and biogenic amines to urine samples from healthy people, who were not given multivitamins tablets. The sample preparation procedure (described before in Urine samples section) has been performed. Chromatographic analysis has been performed twice-first time in the day of sample preparation and second time one week later. Recoveries for biogenic amines and their metabolites are presented in Table 2. Table 3 shows those recoveries for water soluble vitamins. Applied sample preparation method allowed one to obtain recoveries higher than $80 \%$ for examined biogenic amines. Only single values for normetanephrine and serotonin were lower. However, no values were lower than $74 \%$. Recoveries of vitamins for the B group 
Table 1. Retention times and calibration curves parameters for biogenic amines and water-soluble vitamins

\begin{tabular}{|c|c|c|c|c|c|c|}
\hline Compound & $\begin{array}{l}\text { Retention } \\
\text { time (min) }\end{array}$ & Slope & Intercept & $\mathrm{R}^{2}$ & $\begin{array}{c}\text { LOD } \\
\text { ng mL }\end{array}$ & $\begin{array}{c}\mathrm{LOQ} \\
\mathrm{ng} \mathrm{mL}\end{array}$ \\
\hline \multicolumn{7}{|c|}{ Biogenic amines } \\
\hline DOMA & 2.08 & 4000000 & 105965 & 0.999 & 10 & 30 \\
\hline $\mathrm{E}$ & 3.64 & 10000000 & 114242 & 0.999 & 10 & 30 \\
\hline NMN & 4.88 & 10000000 & -15649 & 0.999 & 10 & 30 \\
\hline DA & 6.60 & 7000000 & -172373 & 0.999 & 10 & 30 \\
\hline $\mathrm{MN}$ & 8.64 & 8000000 & 85890 & 0.999 & 10 & 30 \\
\hline MHPG & 11.39 & 6000000 & 162062 & 0.999 & 10 & 30 \\
\hline $5 \mathrm{HT}$ & 17.05 & 2000000 & -138216 & 0.999 & 8 & 24 \\
\hline 5HIAA & 19.97 & 30000000 & -70000000 & 0.997 & 8 & 24 \\
\hline HVA & 22.04 & 9000000 & 1000000 & 0.999 & 8 & 24 \\
\hline \multicolumn{7}{|l|}{ Vitamins } \\
\hline B-1 & 13.76 & 47002 & 2000000 & 0.999 & 100 & 300 \\
\hline B-2 & 26.29 & 41613 & 99026 & 0.997 & 50 & 150 \\
\hline B-3 & 9.89 & 21411 & 515238 & 0.976 & 100 & 300 \\
\hline B-6 & 8.13 & 264220 & -696975 & 0.926 & 100 & 300 \\
\hline B-12 & 28.05 & 16106 & -103035 & 0.953 & 50 & 150 \\
\hline $\mathrm{C}$ & 1.55 & 36439 & -2000000 & 0.998 & 100 & 300 \\
\hline
\end{tabular}

were not lower than $82 \%$ and as much as $76.1-93.5 \%$ for vitamin C. These results clearly show that the applied SPE procedure is suitable for urine samples preparation for analysis of biogenic amines and water soluble vitamins.

The proposed chromatographic system was subsequently used to examine real samples. Urine samples were taken from a patient, who was treated with multivitamin preparation. This preparation contains, among others, vitamins from B group as well as C vitamin (B-1-1.4 mg, B-2$1.6 \mathrm{mg}, \mathrm{B}-3-20 \mathrm{mg}, \mathrm{B}-6-2 \mathrm{mg}, \mathrm{B}-12-6 \mu \mathrm{g}, \mathrm{C}-60 \mathrm{mg}$ ). Samples of $40 \mathrm{~mL}$ were taken three times per day-one hour, four hours, and eight hours after taking multivitamin preparation. Analytes were extracted to a solid phase (Urine samples) and subsequently analyzed using high performance liquid chromatography. The contents of biogenic amines and their metabolites as well as B group vitamins and $\mathrm{C}$ vitamin in urine samples were determined from the calibration curves. Mentioned recoveries allowed one determination of the exact content of the examined compounds. Obtained results are presented in Table 4. The possibility of simultaneous analysis of biogenic amines and vitamins from one sample requires the sample volume to be at least $40 \mathrm{~mL}$.

The following compounds: 3.4-dihydroxyphenylacetic acid $\left(t_{R}=\right.$ $2.81 \mathrm{~min})$, epinephrine $\left(t_{R}=4.02 \mathrm{~min}\right)$, normetanephrine $\left(t_{R}=4.84 \mathrm{~min}\right)$, 
Table 2. Within-day and between-day precision for biogenic amines

\begin{tabular}{|c|c|c|c|c|c|c|c|c|c|}
\hline \multirow[b]{2}{*}{ Compound } & \multirow[b]{2}{*}{$\begin{array}{c}\text { Input } \\
(\mu \mathrm{g} \\
\left.\mathrm{mL}^{-1}\right)\end{array}$} & \multicolumn{4}{|c|}{ Within-day } & \multicolumn{4}{|c|}{ Between-day } \\
\hline & & $\begin{array}{l}\text { Measured } \\
\left(\mu \mathrm{g} \mathrm{mL} L^{-1}\right)\end{array}$ & $\begin{array}{c}\mathrm{SD} \\
(\mu \mathrm{g} \\
\left.\mathrm{mL}^{-1}\right)\end{array}$ & $\begin{array}{l}\mathrm{CV} \\
(\%)\end{array}$ & $\begin{array}{c}\text { Recovery } \\
(\%)\end{array}$ & $\begin{array}{l}\text { Measured } \\
\left(\mu \mathrm{g} \mathrm{mL}^{-1}\right)\end{array}$ & $\begin{array}{c}\mathrm{SD} \\
(\mu \mathrm{g} \\
\left.\mathrm{mL}^{-1}\right)\end{array}$ & $\begin{array}{l}\mathrm{CV} \\
(\%)\end{array}$ & $\begin{array}{c}\text { Recovery } \\
(\%)\end{array}$ \\
\hline \multirow{4}{*}{ DOMA } & 0.20 & 0.17 & 0.15 & 4.0 & 86.7 & 0.19 & 0.06 & 2.4 & 93.3 \\
\hline & 0.30 & 0.27 & 0.38 & 3.5 & 88.9 & 0.27 & 0.36 & 6.4 & 88.9 \\
\hline & 0.40 & 0.33 & 0.23 & 3.2 & 83.3 & 0.39 & 0.23 & 5.7 & 96.7 \\
\hline & 0.10 & 0.08 & 0.06 & 2.6 & 80.4 & 0.10 & 0.14 & 1.4 & 98.2 \\
\hline \multirow[t]{3}{*}{$\mathrm{E}$} & 0.15 & 0.14 & 0.38 & 3.7 & 95.2 & 0.13 & 0.07 & 6.7 & 83.3 \\
\hline & 0.20 & 0.19 & 0.37 & 3.6 & 93.8 & 0.18 & 0.05 & 5.2 & 89.3 \\
\hline & 0.20 & 0.19 & 0.10 & 5.3 & 95.2 & 0.19 & 0.06 & 7.6 & 95.2 \\
\hline \multirow[t]{3}{*}{$\mathrm{NMN}$} & 0.30 & 0.26 & 0.03 & 3.8 & 85.4 & 0.25 & 0.01 & 3.4 & 82.9 \\
\hline & 0.40 & 0.31 & 0.26 & 1.2 & 76.7 & 0.30 & 0.02 & 3.3 & 75.0 \\
\hline & 0.10 & 0.10 & 0.07 & 4.6 & 95.2 & 0.10 & 0.02 & 2.3 & 95.2 \\
\hline \multirow[t]{3}{*}{ DA } & 0.15 & 0.13 & 0.05 & 4.8 & 84.8 & 0.15 & 0.08 & 5.7 & 97.5 \\
\hline & 0.20 & 0.20 & 0.49 & 1.5 & 98.4 & 0.19 & 0.11 & 1.1 & 95.2 \\
\hline & 0.20 & 0.19 & 0.71 & 7.0 & 94.3 & 0.18 & 0.12 & 1.1 & 87.5 \\
\hline \multirow[t]{3}{*}{ NM } & 0.30 & 0.30 & 0.22 & 2.2 & 98.7 & 0.26 & 0.20 & 1.9 & 85.2 \\
\hline & 0.40 & 0.34 & 0.25 & 2.4 & 84.2 & 0.34 & 0.26 & 2.6 & 84.2 \\
\hline & 0.10 & 0.08 & 0.06 & 5.9 & 80.0 & 0.09 & 0.41 & 4.1 & 86.7 \\
\hline \multirow[t]{3}{*}{ MHPG } & 0.15 & 0.14 & 0.05 & 5.0 & 96.7 & 0.13 & 0.41 & 6.7 & 86.7 \\
\hline & 0.20 & 0.19 & 0.48 & 4.7 & 93.2 & 0.19 & 0.41 & 3.4 & 95.5 \\
\hline & 0.20 & 0.16 & 0.04 & 3.6 & 80.7 & 0.15 & 0.08 & 7.8 & 76.6 \\
\hline \multirow[t]{3}{*}{$5 \mathrm{HT}$} & 0.30 & 0.27 & 0.36 & 3.6 & 88.7 & 0.27 & 0.77 & 7.7 & 88.7 \\
\hline & 0.40 & 0.35 & 0.26 & 2.6 & 86.7 & 0.30 & 0.15 & 1.5 & 74.6 \\
\hline & 0.10 & 0.09 & 0.05 & 4.9 & 88.0 & 0.08 & 0.01 & 1.2 & 84.0 \\
\hline \multirow[t]{3}{*}{ 5HIAA } & 0.15 & 0.15 & 0.11 & 1.0 & 98.7 & 0.14 & 0.21 & 2.1 & 90.7 \\
\hline & 0.20 & 0.17 & 0.00 & 0.2 & 84.0 & 0.16 & 0.39 & 3.8 & 82.0 \\
\hline & 0.20 & 0.20 & 0.01 & 1.0 & 97.7 & 0.20 & 0.38 & 3.7 & 97.6 \\
\hline \multirow[t]{2}{*}{ HVA } & 0.30 & 0.29 & 0.22 & 2.2 & 97.8 & 0.24 & 0.14 & 1.3 & 81.5 \\
\hline & 0.40 & 0.37 & 0.18 & 1.7 & 93.5 & 0.39 & 0.07 & 6.8 & 97.6 \\
\hline
\end{tabular}

dopamine $\left(t_{R}=7.49 \mathrm{~min}\right)$, metanephrine $\left(t_{R}=9.16 \mathrm{~min}\right)$, 3-metoxy-4hydroxyphenyl-glycol $\left(t_{R}=11.34 \mathrm{~min}\right)$, serotonin $\left(t_{R}=18.44 \mathrm{~min}\right)$, 5hydroxyindole-3-acetic acid $\left(t_{R}=20.49 \mathrm{~min}\right)$ and homovanillic acid $\left(t_{R}=23.13 \mathrm{~min}\right)$, as well as $\mathrm{B}-1\left(t_{R}=13.90 \mathrm{~min}\right), \mathrm{B}-2\left(t_{R}=26.10 \mathrm{~min}\right)$, B-3 $\left(t_{R}=9.48 \mathrm{~min}\right), B-12\left(t_{R}=27.48 \mathrm{~min}\right)$, and $C\left(t_{R}=1.60 \mathrm{~min}\right)$ water soluble vitamins, have been determined in examined urine samples taken from people treated with a multivitamin preparation. The B-6 vitamin has not been found in any of real urine samples. Exemplary chromatograms of urine sample taken from a person treated with multivitamin preparation are shown on Figures $3 a$ and $3 b$. Chromatogram 3a comes from 


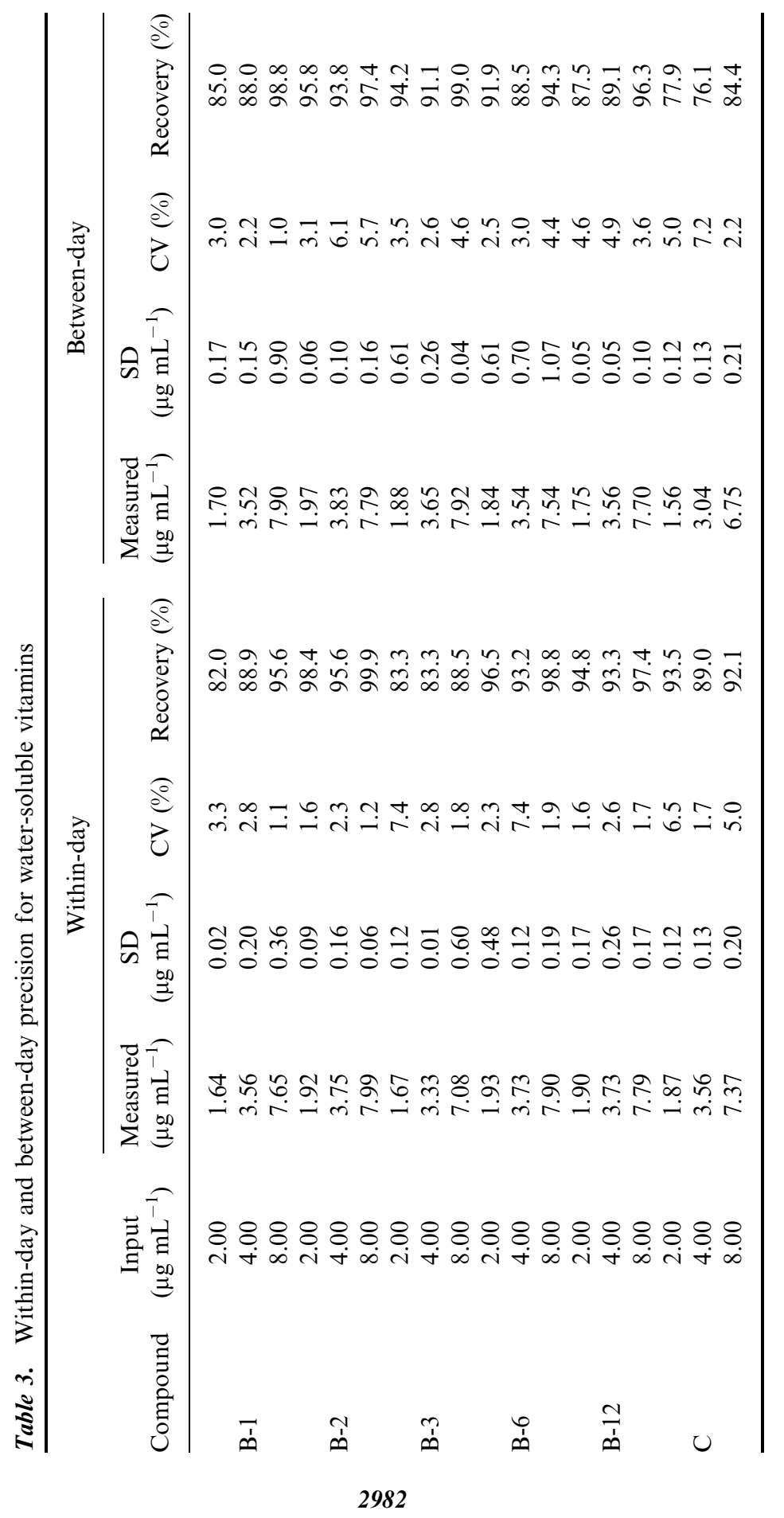




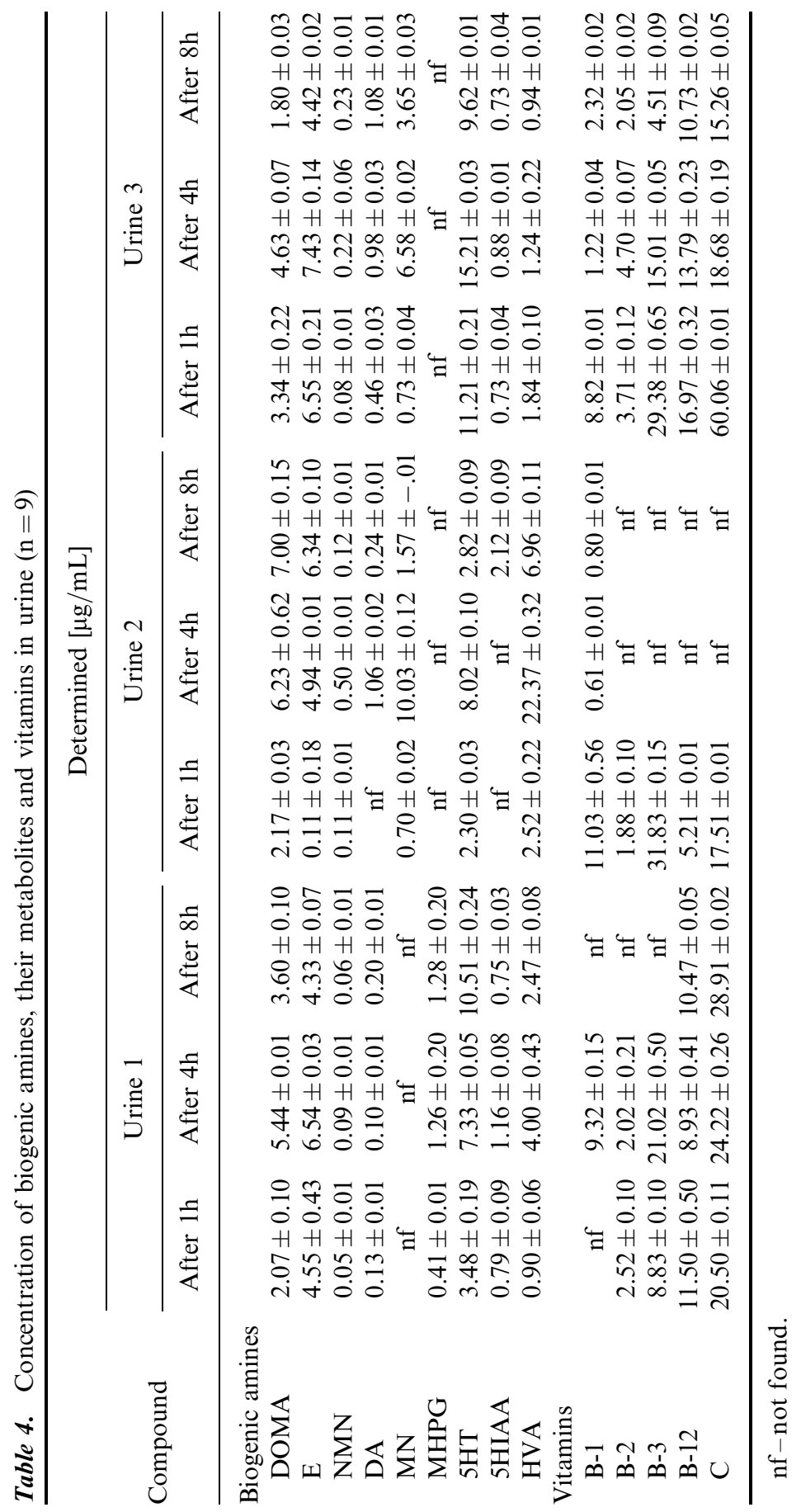




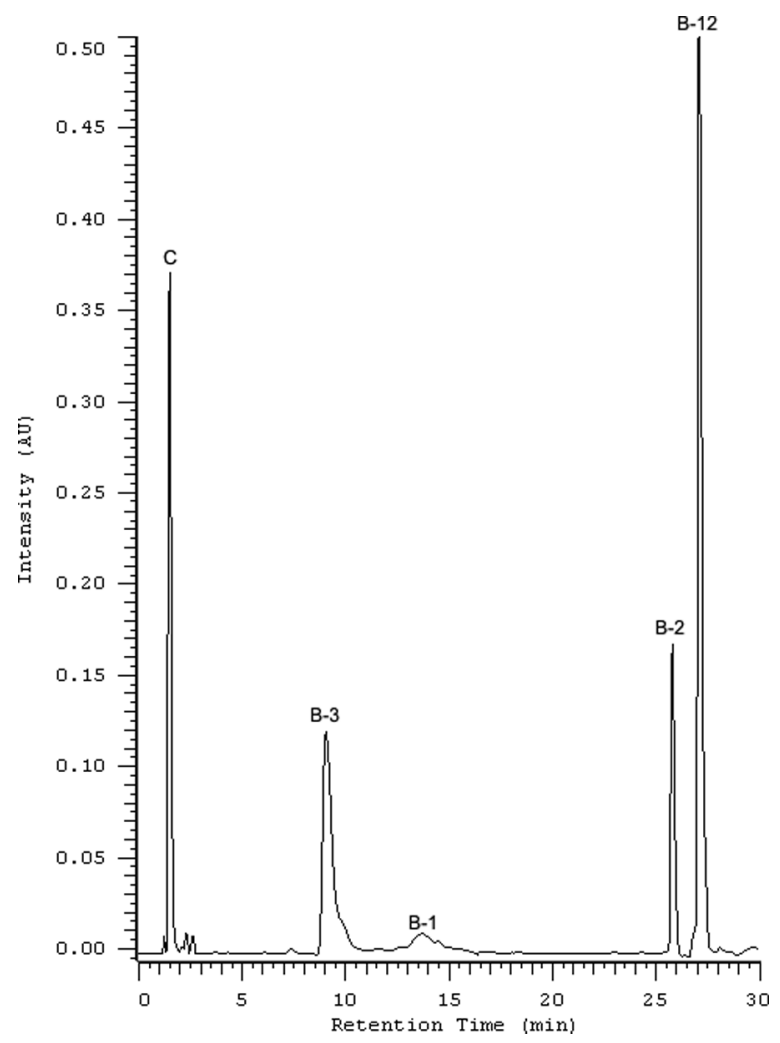

Figure 3. (a) Chromatogram of vitamins in real urine sample (DAD detector). (b) Chromatogram of biogenic amines in real urine sample (FL detector).

the DAD detector and present vitamins, while chromatogram $3 \mathrm{~b}$ comes from the FL detector and present biogenic amines.

A chromatogram of vitamins has been recorded with the same parameters as the chromatogram of standards. The minor differences between retention times of the analytes in model samples and real urine samples can be explained as a result of matrix effect. The presence of particular analytes has been confirmed by the standard addition method. In the case of vitamins, UV spectra of examined compounds and standards have been compared. B-1, B-2, and B-6 vitamins fluoresce; thus, they can be detected simultaneously with both detectors, i.e., DAD and FL. However, for excitation and emission wavelengths used for biogenic amines and their metabolites analysis, only the B-6 vitamin can be detected with use of the FL detector.

The developed chromatographic system allows one to analyze the content of nine biogenic amines and their metabolites, as well as five 


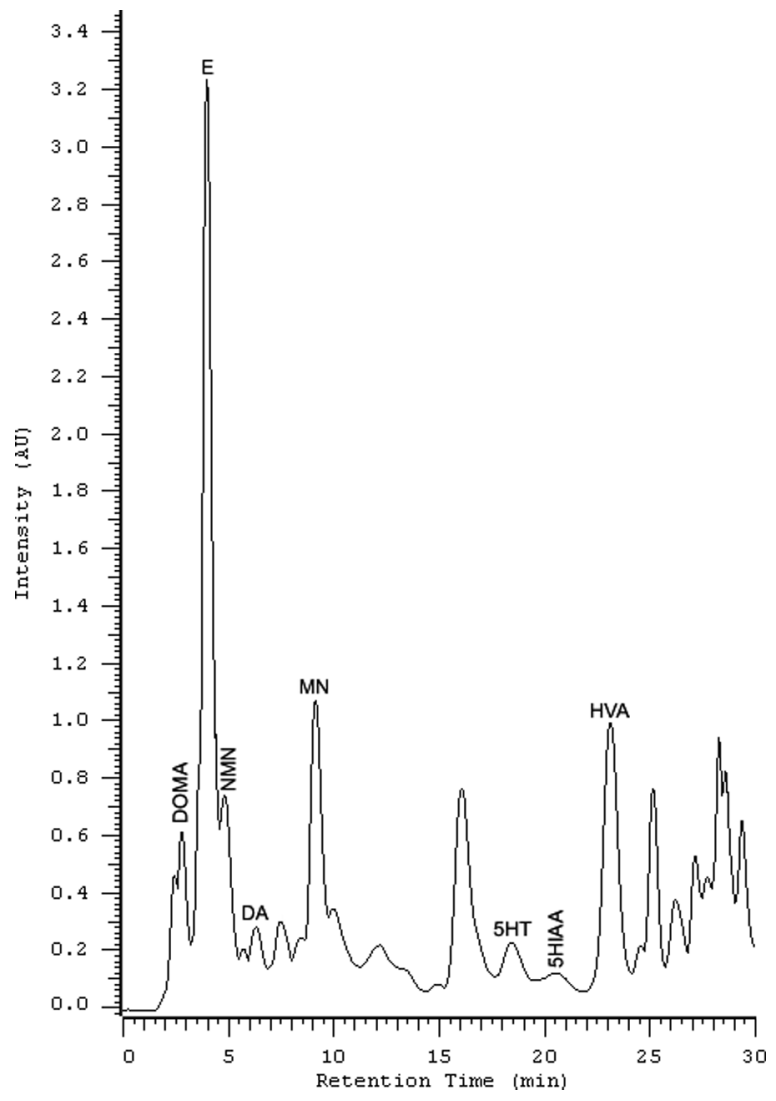

Figure 3. Continued.

water soluble vitamins. These compounds can be determined simultaneously. Moreover, the sample preparation for analysis does not require different procedures for biogenic amines and vitamins.

\section{ACKNOWLEDGMENTS}

This work was supported from science funds for scientific research for years 2007-2009, as Project No. N20402532/0738.

\section{REFERENCES}

1. Sirén, H.; Karjalainen, U. Study of catecholamines in patient urine samples by capillary electrophoresis. J. Chromatogr. A. 1999, 853, 527-533. 
2. Brambilla, F.; Bellodi, L.; Arancio, C.; Ronchi, P.; Limonta, D. Central dopaminergic function in Anorexia and Bulimia Nervosa: a psychoneuroendocrine approach. Psychoneuroendocrino. 2001, 26, 393-409.

3. Bates, C. Riboflavin. Int. J. Vitam. Nutr. Res. 1993, 63, 274-277.

4. Nishijima, S.; Sugaya, K.; Morozumi, M.; Hatano, T.; Ogawa, Y. Hepatic alanine-glyoxylate aminotransferase activity and oxalate metabolism in vitamin B6 deficient rats. J. Urol. 2003, 169, 683-686.

5. Leafa, A.; Subramanianb, S.; Cheriana, S. Vitamins for preterm infants. Curr. Paediat. 2004, 14, 298-305.

6. Lazzarini, M.; Salum, C.; Del Bel, E.A. Combined treatment of ascorbic acid or alpha-tocopherol with dopamine receptor antagonist or nitric oxide synthase inhibitor potentiates cataleptic effect in mice. Psychopharmacology 2005, 181, 71-79.

7. Herrmann, W.; Geisel, J. Vegetarian lifestyle and monitoring of vitamin B-12 status. Clin. Chim. Acta 2002, 326, 47-59.

8. Depeint, F.; Bruce, W.R.; Shangari, N.; Mehta, R.; O’Brien, P.J. Mitochondrial function and toxicity: role of the $\mathrm{B}$ vitamin family on mitochondrial energy metabolism. Chem.-Biol. Interact. 2006, 163, 94-112.

9. Boyland, L.M.; Hart, S.; Porter, K.B.; Driskell, J.A. Vitamin B-6 content of breast milk and neonatal behavioral functioning. J. Am. Diet. Assoc. 2002, 102, 1433-1438.

10. de Lau, L.M.L.; Koudstaal, P.J.; Witteman, J.C.M.; Hofman, A.; Breteler, M.M.B. Dietary folate, vitamin B12, and vitamin B6 and the risk of Parkinson disease. Neurology 2006, 67, 315-318.

11. Baranowska, I.; Zydroń, M. Analysis of biogenic amines, alkaloids and their derivatives by TLC and HPLC. J. Planar Chromatogr. 2000, 13, 301-306.

12. Baranowska, I.; Zydroń, M. Liquid chromatography in the analysis of neurotransmitters and alkaloids. J. Chromatogr. Sci. 2002, 40, 224-228.

13. Baranowska, I.; Zydroń, M. Determination of biogenic amine neurotransmitters by RP-HPLC/FL method on Chromolith RP18e stationary phase. J. Sepn. Sci. 2003, 26, 614-618.

14. Baranowska, I.; Zydroń, M. Quantitative structure-retention relationships (QSRR) of biogenic amine neurotransmitters and their metabolites on RP18 plates in thin-layer chromatography. J. Planar Chromatogr. Mod. TLC. 2003, 16, 102-106.

15. Baranowska, I.; Zydron, M. Effect of mobile-phase $\mathrm{pH}$ on the chromatographic behavior of biogenic amine neurotransmitters and their metabolites. J. Planar Chromatogr. Mod. TLC. 2004, 17, 297-299.

16. Baranowska, I.; Zydroń, M. Retention-mobile phase relationships for methylxanthines and biogenic amine metabolites in adsorption thin-layer chromatographic systems. J. Planar Chromatogr. Mod. TLC. 2004, 17, 233-237.

17. Zydroń, M.; Baranowski, J.; Białkowski, J.; Baranowska, I. HPLC-FL/ED in the analysis of biogenic amines and their metabolites in urine. Sepn. Sci. Technol. 2005, 40, 3137-3148. 
18. Kema, I.P.; de Vries, E.G.E.; Muskiet, F.A.J. Clinical chemistry of serotonin and metabolites. J. Chromatogr. B. 2000, 747, 33-48.

19. Cheng, F.-C.; Kuo, J.-S. High-performance liquid chromatographic analysis with electrochemical detection of biogenic amines using microbore columns. J. Chromatogr. B. 1995, 665, 1-13.

20. Zhu, X.; Shaw, P.N.; Barrett, D.A. Catecholamines derivatized with 4-fluoro7-nitro-2,1,3-benzoxadiazole: characterization of chemical structure and fluorescence properties. Anal. Chim. Acta 2003, 478, 259-269.

21. Cho, C.M.; Ko, J.H.; Cheong, W.J. Simultaneous determination of water-soluble vitamins excreted in human urine after eating an overdose of vitamin pills by a HPLC method coupled with a solid phase extraction. Talanta 2000, 51, 799-806.

22. Rössler, J.; Breitenstein, S.; Havers, W. Megaloblastäre anämien durch vitaminB12-mangel im kindesalter. Monatsschr Kinderheilkd. 2001, 149, 497-503.

23. Baranowska, I.; Płonka, J. Determination of levodopa and biogenic amines in urine samples using high performance liquid chromatography. J. Chrom. Sci. 2008, 46, 30-34.

Received October 18, 2007

Accepted April 30, 2008

Manuscript 6230 
Copyright of Journal of Liquid Chromatography \& Related Technologies is the property of Taylor \& Francis Ltd and its content may not be copied or emailed to multiple sites or posted to a listserv without the copyright holder's express written permission. However, users may print, download, or email articles for individual use. 